\title{
Correlation of Electrical Resistivity of Soil with Geotechnical Parameters (Atterberg Limits) at Gombe, Northern Nigeria
}

\author{
Abubakar Magaji*, Mathias Yakubu and Yakubu Mammam Wakawa \\ Department of Civil Engineering Federal Polytechnic, Mubi Adamawa State Nigeria.
}

\begin{abstract}
Electrical resistivity technique is a popular alternative method used in geotechnical soil investigations. Most past applications have been particularly in the area of subsurface ground investigations such as to locate boulder, bedrock, water table, etc. Traditionally, this method was performed by a geophysicist expert for data acquisition, processing and interpretation. The anomalies highlighted uncertainties on the nature of soil that was often variable and depended on each particular site condition that gave a site dependent soil electrical resistivity value. In order to establish empirical equations that relate layer resistivity values with geotechnical parameters for engineering site characterization, samples collected from four different boreholes drilled to a maximum depth of $40 \mathrm{~m}$ meters, samples were collected at $10 \mathrm{~m}$ interval which were used in the correlation. Schlumberger array with 300c model of ABEM Terrameter SAS was used in the survey, and later interpreted using WINRESIST2 the interpreted models indicate four layers interpreted as topsoil, weathered sand, silty sand and sandy clay. Atterberg limit test was conducted on the disturbed soil samples. The geo-electrical data and geotechnical parameter were subsequently correlated. The study established that soil electrical resistivity increases with increase in Liquid limit but decreases with increase in plasticity index. Where the correlation coefficients are significant as for plasticity index, the established empirical equations can be used to estimate geotechnical properties from subsoil resistivity values, thereby reducing the cost and duration of engineering site investigation.
\end{abstract}

Keywords: Anomaly, Resistivity, Atterberg limits, Schlumberger array, Empirical Equation

\section{Introduction}

The importance of resistivity survey in subsurface investigation is gaining relevance in site geotechnical exploration all over the world. It is a simple and straight forward technic in exploring subsurface. Geotechnical engineers are able to investigate various parameters through conventional soil test boring, but they can only get some information for a particular area and have to do extrapolation to get larger coverage. In contrast resistivity survey can provide detailed image of the subsurface as well as qualitative information.

Analyzing geotechnical parameters is an important issue for rigorous use of resistivity approach in engineering applications. The relationship between different geotechnical properties with resistivity survey can bridge the gap that already exists between geophysical testing and geotechnical engineering which can assist geotechnical engineers in analyzing information for their design which make this new nondestructive approach important in modern geotechnical society.

The current research is trying to find the correlation between geophysical approaches with geotechnical engineering. This phenomenon is trying to utilize the correlation that exist between electrical and geotechnical parameters of soil. The following are some of the factors that affect the resistivity of materials like moisture content, unit weight, specific surface area (SSA), percentage of pores, and degree of saturation. Clear understanding of the causes of variation of the above listed factors that affect resistivity will help in developing proper correlations between geotechnical parameters and electrical resistivity. 
Researchers like (Hassanein et al., 1996) correlate electrical resistivity with several soil parameters, such as hydraulic conductivity and some index properties of clays. A previous research by Kalinski and Kelly (1994) suggested the possibility of correlating geoelectrical property with hydraulic conductivity that can serve as a nondestructive way of examining the quality of compacted soil. (Pozdnyakava et al., 2001) have done comprehensive research on the effect of electrical resistivity on different soil types that has different water contents, salt contents and other parameters.

Researchers like Ronald and Ronald(1982) also tried to establish the effect of resistivity on soil liquefaction, so various research works have been conducted around the world trying to establish the relationship between geophysical and geotechnical methods. Researchers like Siddiqui and Osman (2012) conducted research trying to correlate geotechnical index properties with geophysical methods in Malaysia. (Cosenza et al., 2006), correlated the geotechnical and electrical data in France (Garchy).

Electrical resistivity was compared with Atterberg limits by (Abu-Hassanein et al., 1996) of compacted clays to optimum moisture by modified Proctor compaction system. The result indicated a reciprocal relationship between electrical resistivity and liquid limit (LL), and plasticity index (PI). It shows consistency with the mineralogy of the clay. The higher percentage of smectite gives higher liquid limit and plasticity index. Smectite-type of clay shows enhancing conductivity which will clearly yield greater conductivity with rising quantity.

This research work involves preliminary site investigation (reconnaissance survey) such as open well studies within the survey sites, descriptive surface lithologies, outcrop types and topographic controls, structural lineaments and orientations and electrical drilling method or VES surveys for definition of aquifer depths, weak zone distribution and apparent resistivity sections, as contrasted to geologic sections.

Geophysical surveys are basically the interpretation of variation in measured responses, either naturally or artificially generated within the earth crust. Such variation results from the difference in some notable properties like elasticity, magnetism, density, electrical resistivity of soils in the area of interest. In this work observed data was interpreted by means of computer software (WINGRESIST2) and the final results were then used to correlate with Atterberg limits.

\section{The Study Area}

The study area is located in the Upper Benue Trough, and is characterized by few high and low level outcrops. Major part of the study area is overlain by coarse sandy soil believed to be weathering product of the preexisting rocks. This research is vital because it would produce a comprehensive correlation of electrical resistivity of soil with geotechnical parameters (Atterberg limits) at Gombe, Northern Nigeria. A total of four different areas were studied in which borehole of depth $40 \mathrm{~m}$ were dug and samples were collected at $10 \mathrm{~m}$ intervals corresponding to electrical resistivity (VES) measurement locations. Atterberg limit tests were conducted on each of the samples which were later correlated with resistivity values.

\section{Significance Of The Study}

The main target of this research is the determination of geotechnical index properties of soil by employing geophysical and geotechnical techniques. It complements a well-planned, cost-effective drilling and testing program, and may provide a volumetric image of the subsurface rather than point assessments. 


\section{Literature Review}

\section{Previous Studies Undertaken On Correlation}

Some researchers correlated consistency limits with inverse of conductivity to determine the relation of compacted clays with maximum water percentage, employing modified compaction method. It shows inverse of conductivity diminished by raising liquid limit (LL) and plasticity index (PI). The trend is consistent with mineralogy of the clay. Soils with clay comprising greater percentage of smectite usually had greater (LL) and (PI). Smectite clays tend to exhibit higher surface conductivity with rising quantity. Thus, higher surface conductivity yields lower resistivity. Figure 2.10 is a plot of liquid limit (LL) and plasticity index (PI) versus the inverse of resistivity of some selected samples (Abu-Hassanein et al. 1996).

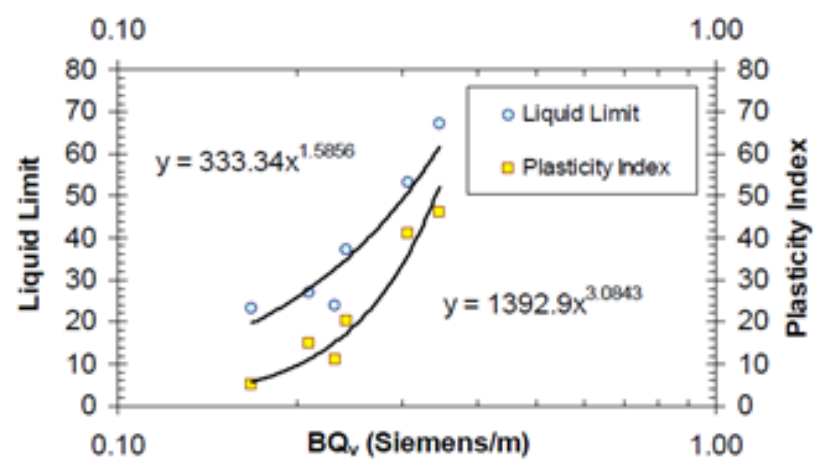

Figure 2.9 Relationship of inverse of resistivity and consistency limit (data From Abu-Hassanein et al., 1996).

This sketch shows that raising surface conductivity corresponds to increasing liquid limit (LL) and plasticity index (PI) values. This figure further reveals that the Atterberg limits of clay lead to a power function of the surface conductivity, with the surface conductivity implying a lightly better sign of liquid limit than plasticity index. Some correlation connecting the Atterberg limits and surface conductivity is provided as

$L L=\alpha_{1}\left(\beta Q_{V}\right)^{\beta 1}$

$\mathrm{PI}=\alpha_{2}\left(\beta Q_{\mathrm{V}}\right)^{\beta 2}$

Where $\alpha 1=3.33, \beta 1=1.59, \alpha 2=13.93$, and $\beta 2=3.08$

The consistency limits were in decimals $\alpha$ and $\beta$ values are the common possible functions of this clay mineralogy. It is assumed the inverse of resistivity of clay is applied as an efficient way to presume consistency limit. That is due to the fact consistency limit of non-expanding clay is relatively affected by diffuse double layer. The probability is consistency limit and inverse of resistivity of non-expanding clay rise with rising width of the diffuse double layer (Mitchell et al., 1993).

\section{Methodology}

This research work involves preliminary site investigation (reconnaissance survey) such as open well studies within the survey sites, descriptive surface lithology's outcrop types and topography of the area. Electrical drilling method or VES surveys for definition of layer depths, weak zone distribution and apparent resistively sections as contrasted to geologic sections. Geophysical surveys are basically the interpretation of variation in 
measured responses, either naturally or artificially generated within the earth crust. Such variation results from the differences in some notable properties like elasticity, magnetism, density, electrical resistivity below the area of interest. In this work, observed data were interpreted by means of computer software and the final results were then used to correlate with Atterberg limits of the soils within the study area.

\section{Selection of Sampling Sites}

To choose potential sampling positions, Google Earth map was used to identify the location of Gombe/Northern Nigeria. As this is an initial investigation it was decided to limit the possible sampling sites within Gombe town. When choosing potential sampling positions the important factors considered were the site to be situated in the Gombe formation and to assure specimens covered an adequate section of this area. The total area that these sites represented is approximately $1 \mathrm{~km}^{2}$. Arrangements were made to gain access to the site.

\section{Collection of Disturbed Samples}

Air percussion method was used in drilling the borehole. It was aimed to penetrate to depth of about $40 \mathrm{~m}$, collecting samples at $10 \mathrm{~m}$ intervals. Prior to the collection of the disturbed samples, containers were washed to avoid mixing of possible dirt with the collected specimens. The samples collected were placed in clean plastic trays. The quantity of sample needed to perform the soil analyses was about 1 kilogram. The disturbed samples were placed in air sealed plastic containers with labelled tags to avoid mixing of the samples.

\section{Laboratory Examination}

Testing was performed in a laboratory accredited by the National Board for Technical Education (NBTE), a regulatory body in education sector in Nigeria. The laboratory experiments were done in the soil laboratory of Federal Polytechnic Mubi, Nigeria, The laboratory is approved for the following experiments:

- Liquid limits Determination of a soil - One point Casagrande method.

- Plastic limits Determination of a soil - Standard method.

- Plasticity index of a soil.

- Linear shrinkage Determination of a soil - Standard method.

\section{Basic Principle For Resistivity Survey}

In the uniform ground, current passes out from the origin through a hemispheric surface. The current frequency is equivalent everywhere on the surface which is also called an equivalent potential. Ohm's law (V=IR) being the genesis, the resistance $\mathrm{R}$ in terms of the resistivity $\rho$ and the section of the shell (equipotential surface), the voltage over the shell is $\mathrm{dV}=$

$$
\mathrm{R}=\frac{\rho \mathrm{l}}{\mathrm{A}}
$$

The potential difference across the shell is $\mathrm{dv}=$

$$
d v=i(R)=I\left(\frac{\rho l}{A}\right)=I\left(\rho \frac{d r}{2 \pi r^{2}}\right)
$$


$\mathrm{V}$ represents voltage, I represent current, $\rho$ represent resistivity, and $\mathrm{r}$ represents the radius of the equipotential surface. Combining the above relation and establishing the potential, the electric potential at a range $\mathrm{R}$ from the origin is given by

$$
\mathrm{V}=\frac{\rho \mathrm{I}}{2 \pi \mathrm{R}}
$$

Where $\rho$ is constant called the resistivity of material to have a better understanding of resistivity, it will be very important to appreciate the behavior of electric current as it passes through a layered media, which is invariably the case rather than a homogeneous earth and how this affect the distribution of potentials through the ground. In most cases of interpretation of resistivity data, the ground is considered as being made of approximately constant resistivity layers bounded from each other of different resistivity by plane interfaces. This corresponds to region of different geological composition. To have a good perspective of the principles of geoelectric prospecting method, it will be very paramount to understand the behavior of electric current as it goes around a layered media, which is invariably the case rather than homogeneous earth, and how this affect the distribution of current through the ground. In most cases the translation of resistivity data the ground is considered as being made of approximately uniform resistivity layers bounded from others of different resistivity by the plane interface.

In general, thus corresponds to the area several geological compositions. In practice, current electricity is sent through the earth at one point $\mathrm{C}$ and leaves at another point $\mathrm{C} 2$. The resultant voltage is measured between two potential electrodes $\mathrm{P} 1$ and $\mathrm{P} 2$, where the potential difference DV is measured by the differences in the respective potential $\mathrm{V} 1$ and $\mathrm{V} 2$ at $\mathrm{PI}$ and $\mathrm{P} 2$ as:

$\mathrm{DV}=\mathrm{V}_{\mathrm{p} 1}-\mathrm{V}_{\mathrm{p} 2}$

Where VP1 and VP2 are the potential differences generated at P1 at P2 due to currents source and sink at C and $\mathrm{C}$ respectively. Therefore equation (1) becomes;

$\mathrm{AV}=\frac{\mathrm{P} 1}{2 \pi}\left[\left(\frac{1}{\mathrm{r} 1}-\frac{1}{\mathrm{r} 2}\right)-\left(\frac{1}{\mathrm{r} 3}-\frac{1}{\mathrm{r} 4}\right)\right]$

$\mathrm{P}=\mathrm{Rk}$ where $\mathrm{k}$ is known as the geometric factor which relates to the spacing between electrodes and their arrangement and $\mathrm{P}$ is the resistively of a homogeneous earth as defined in figure 2 .

\section{Correlation And Regression}

This correlation investigation was done in order to evaluate the intensity of a linear or nonlinear relation connecting two continuous parameters. While, simple regression the analysis is to assess the relevant influence of a predictor the variable base on a particular result. The correlation and Regression is conducted using Microsoft Excel. The equation obtained from correlation and regressions precisely Pearson method to get the coefficient of determination. Some interpretation of coefficient can be seen as in order to define the power and rank of the correlation 
Table 3.1 Ranges of $R 2$ correlation coefficient.

\begin{tabular}{ll}
\hline Size of correlation & Strength of correlation \\
\hline $0.9-1.0$ & Highly Perfect/ Very strong \\
$0.7-0.9$ & Perfect/ strong \\
$0.5-0.7$ & Moderate \\
$0.3-0.5$ & Weak \\
$0.0-0.3$ & No association \\
\hline
\end{tabular}

\section{Results And Discussion}

\section{Resistivity Values And Its Interpretation}

\begin{tabular}{cccccc}
\hline \multicolumn{1}{l}{ VES no. Layers } & Resistivity & Thickness & Depth & Lithology \\
\hline 1 & 1 & 13.1 & 9.1 & 9.1 & Dry Top Soil \\
& 2 & 78.3 & 13.7 & 22.8 & Weathered sand \\
& 3 & 11.2 & 44.6 & 67.4 & Silty Sand \\
& 4 & 17.4 & - & - & Silty Sand \\
\hline 2 & 1 & 13.9 & 9.4 & 9.4 & Dry Top Soil \\
& 2 & 107.4 & 13.3 & 22.6 & Weathered Sand \\
& 3 & 21.2 & 30.5 & 53.1 & silty Sand \\
& 4 & 22.8 & - & & silty Sand \\
\hline 3 & 1 & 13.5 & 8.9 & 8.9 & Dry Top Soil \\
& 2 & 96.1 & 11.6 & 20.5 & Weathered Sand \\
& 3 & 14.9 & 29.0 & 49.5 & Silty Sand \\
& 4 & 15.1 & - & - & Silty Sand \\
\hline 4 & 1 & 16.4 & 10.9 & 10.9 & Dry Top Soil \\
& 2 & 106.0 & 8.3 & 19.2 & Weathered Sand \\
& 3 & 191.6 & 20.4 & 39.6 & Silty Sand \\
& 4 & 162.2 & - & - & Silty Sand \\
\hline
\end{tabular}

\section{Atterberg Limits}

Atterberg limits test is generally accepted method for ascertaining and describing the consistency of cohesive soil in giving valuable data concerning soil strength, behavior, stability, type and state of consolidation besides its application in soil classification. Consistency is generally employed to describe the degree of firmness (e.g soft, medium, firm, or hard) and the consistency of cohesive soil is greatly influenced by the water content of the soil. A progressive increase of the water content, for instance, may change dry clay from maybe a solid state to a semi-solid state, to a plastic state and after further moisture increase, rise into a liquid state. The water content at the similar limits on these states is referred to as the shrinkage limit, plastic limit, and the liquid limit respectively. 
Table 4.10 Atterberg limits lesults.

\begin{tabular}{llllll}
\hline S/NO. & $\begin{array}{l}\text { Depth of } \\
\text { Sample }(\mathbf{m})\end{array}$ & $\begin{array}{l}\text { Liquid Limit } \\
(\boldsymbol{\%})\end{array}$ & $\begin{array}{l}\text { Plastic Limit } \\
(\boldsymbol{\%})\end{array}$ & $\begin{array}{l}\text { Plasticity Index } \\
(\boldsymbol{\%})\end{array}$ & $\begin{array}{l}\text { Linear Shrinkage } \\
(\boldsymbol{\%})\end{array}$ \\
\hline BH1 & 10 & 25 & 9.2 & 15.7 & 5.9 \\
& 20 & 28 & 18.5 & 9.4 & 6.1 \\
& 30 & 27 & 14.4 & 12.6 & 5.9 \\
& 40 & 25.5 & 19.3 & 6.2 & 5.9 \\
\hline BH2 & 10 & 23 & 12.7 & 10.3 & 5.47 \\
& 20 & 27 & 19.5 & 7.5 & 5.9 \\
& 30 & 26 & 14 & 11.9 & 6.1 \\
& 40 & 25.5 & 19.5 & 6 & 5.7 \\
\hline BH3 & 10 & 20.5 & 12.2 & 8.3 & 5.23 \\
& 20 & 26.5 & 18.9 & 7.6 & 5.9 \\
& 30 & 27 & 13.8 & 13.2 & 5.94 \\
& 40 & 26 & 19.4 & 6.6 & 5.23 \\
\hline BH4 & 10 & 25 & 10.1 & 14.9 & 5.71 \\
& 20 & 27 & 18.3 & 8.7 & 5.94 \\
& 30 & 27 & 13.2 & 13.8 & 5.47 \\
& 40 & 25.5 & 19.2 & 6.3 & 5.47 \\
\hline
\end{tabular}

\section{Correlation of Results}

Figure 4.6 (a)-(d) presents the relationship between the Atterberg limits and resistivity values of specimens collected at $10 \mathrm{~m}$ intervals down to $40 \mathrm{~m}$ at the surveyed area. The results reveal that the correlation decrease with depth, the top $10 \mathrm{~m}$ give a very good correlation strength of which is classified as "strong" according to Table 3.1 which classifies the rank of correlations. The increment of electrical resistivity values indicate increase of liquid limit of the fines in sandy layers, which is in good agreement with the previous findings (AbuHassanein et al. 1996). The equations of the straight line fits are quite close to each other. Hence this is another indication of a good correlation between liquid limit and electrical resistivity. 


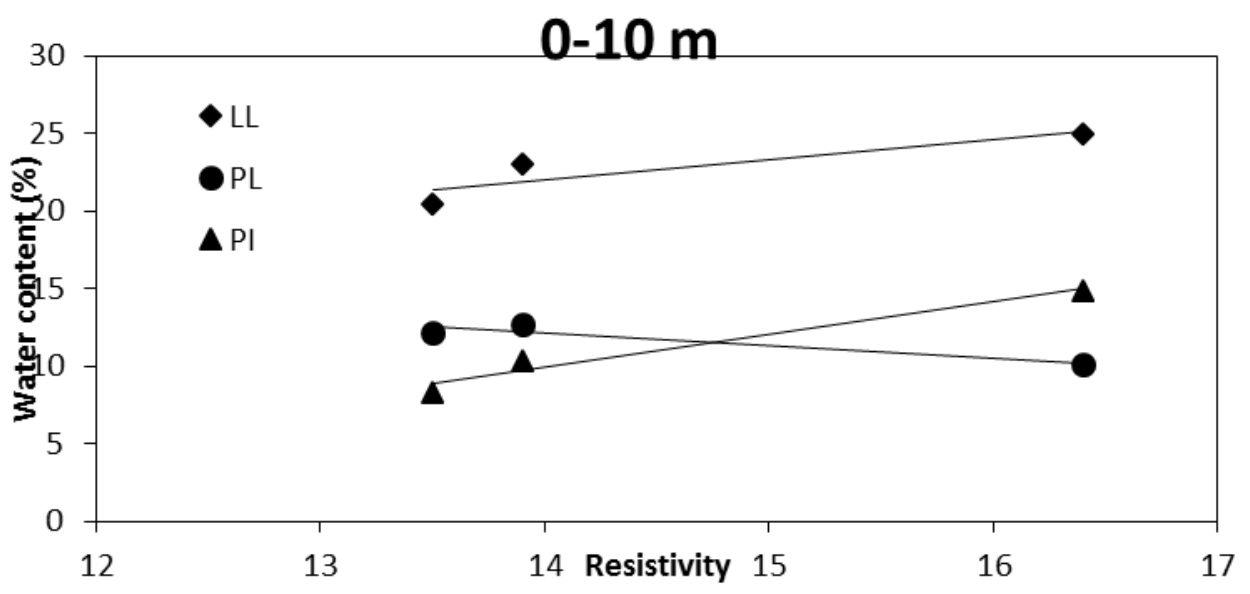

(a)

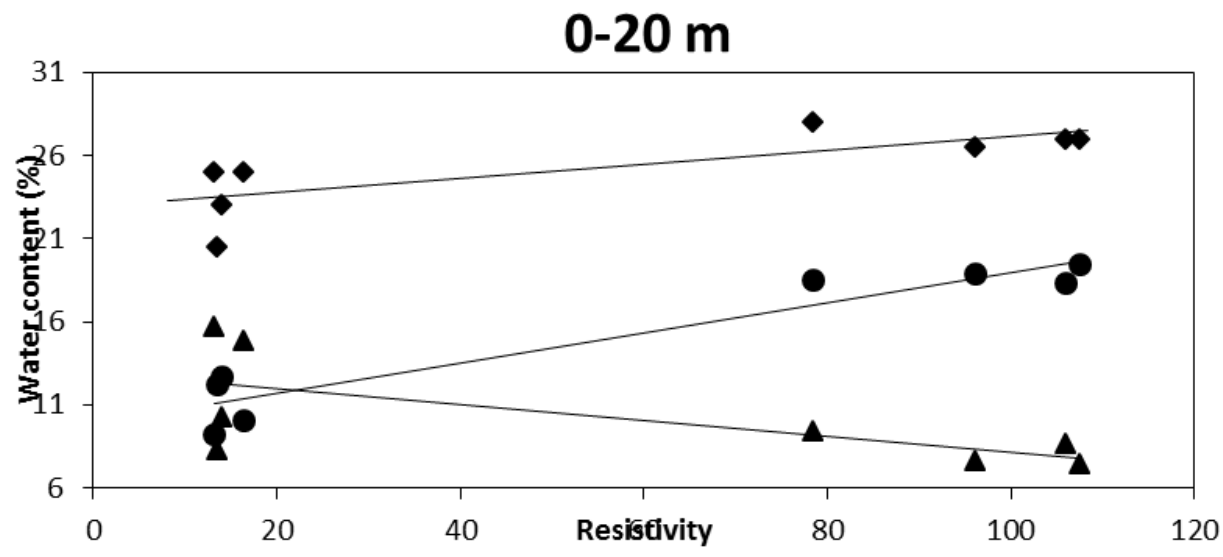

(b)

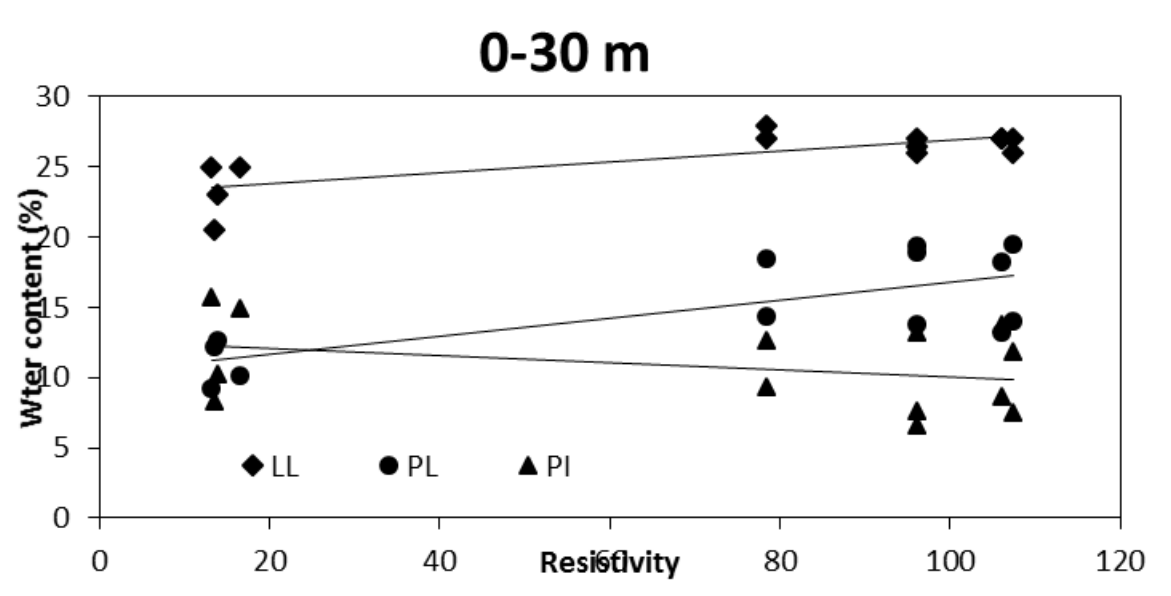

(c) 


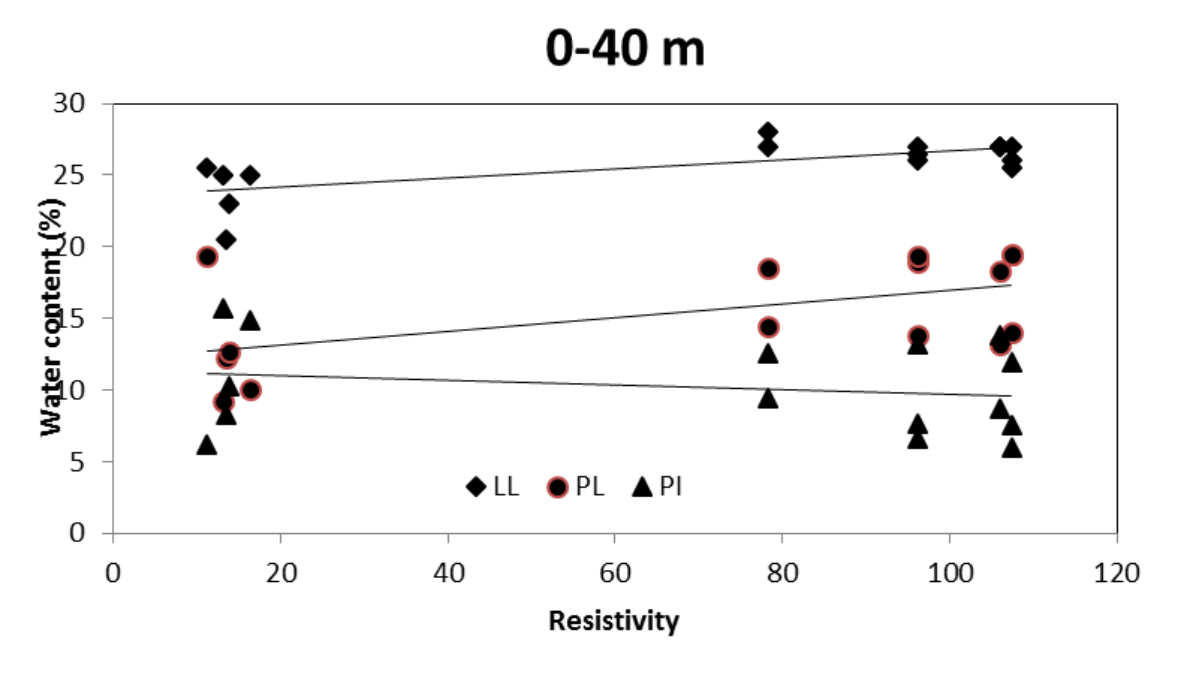

(d)

Figure 4.1 Cont.

Figure 4.1 Correlations of Atterberg limits for $10 \mathrm{~m}$ interval of the soils surveyed.

Table 4.1 Regression Values (R2)

\begin{tabular}{llll}
\hline DEPTH & LL & PL & PI \\
\hline $0-10 \mathrm{~m}$ & 0.8029 & 0.9706 & 0.907 \\
$0-20 \mathrm{~m}$ & 0.6003 & 0.9028 & 0.4476 \\
$0-30 \mathrm{~m}$ & 0.5912 & 0.5257 & 0.1149 \\
$0-40 \mathrm{~m}$ & 0.481 & 0.3014 & 0.0466
\end{tabular}

Based on these findings, it can be deduced that the deeper it the less we obtained good correlation, due to the penetration power, as the electrical current loses strength with depth.

\section{Conclusion and Recommendation}

\section{Conclusion}

The geophysical survey employed the vertical electrical sounding technique using Schlumberger configuration. A total of four soundings were carried out. The geotechnical aspect involved the drilling of four boreholes to a depth of $40 \mathrm{~m}$ at locations which coincide with vertical electrical sounding (VES) point strategically distributed within the survey site. Atterberg limits tests were carried out on each sample taken at $10 \mathrm{~m}$ interval in each borehole within the area, to investigate its in-situ relation to the electrical property of the soil. Although Atterberg limits give important information, this data is limited to the area of the measurement. The geophysical results show four layers within the study area, which include the topsoil (dry), with coarse sand, lateritic clayey 
sand. The second layer is composed of weathered sand, the third and fourth layers are composed of silty sand. Results of the geophysical study further show that the study area is of average resistivity value with the

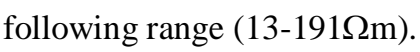

This research could be regarded as s initial investigation as it is based on only sixteen soil samples, four from each borehole that has been collected and tested. A correlation is considered as a valuable tool for predicting the engineering properties with a coefficient of regression value (R2) of at least 0.80 . It was observed that the two properties that present a satisfactory correlation is the liquid limit and electrical resistivity which have been altered by both the percentage of clay and silt particles already present in the soil.

\section{Recommendations for Further Work}

In this research, it has become obvious that it may be possible to develop better correlations provided the following are taken into consideration in further studies:

- Additional sampling and testing should be conducted to reduce the impact of any likely outliers that may be present, hence increasing the $\mathrm{R} 2$ coefficient.

- Further investigation should be done on whether a correlation exists linking the electrical resistivity and the plasticity index or liquid limit of different clay types.

- Effectiveness of different geophysical techniques in general applications should also be considered (e.g. comparing seismic and resistivity downhole testing).

This research only focused on soils from a particular area within Gombe, Northern Nigeria. Future work could be conducted using related analysis methods for other geological formations.

\section{References}

Abu zeid, M. M., (2009). Evaluation of Expansive Soil Properties by Electrical Resistivity: A Thesis Submitted for the Degree of Master of Science in Civil Engineering, Minia University, Egypt.

Abu-Hassanein, Zeyad S., (1996). Electrical Resistivity of Compacted Clays". Journal of Geotechnical Engineering, 122(5), 397-406.

Agunloye O. et al. (1984). Soil Aggressive along steel pipeline route at Ajaokuta. Journal of Mining Geology, 21(12), 97-10

Akinlabi I.A. and Oladunjoye M.A. (2008). Geophysical Investigation of Damsite in a Sedimentary Terrain: A Case study. Research Journal of Applied Sciences, 3(7), 484-489.

Akintorinwa, O.J et al. (2011). Appraisal of the Causes of Pavement Failure Along The Ilesa -Akure Highway, Southwestern Nigeria Using Remotely Sensed and Geotechnical Data, life Journal of Science, 13(1), 185-197.

Amgad. E. S, (2005). Correlations between the Electrical Resistivity and Some Properties of Clayey Soil Thesis submitted for the degree of Master of Science in Civil Engineering, faculty of Engineering, Minia University.

Avbovbo, A. A., (1978). Tertiary lithostratigraphy of Niger Delta. Bulletin of American Association of Petroleum Geology, 62, 297-306

Benkhelil, M.J. (1989). The Origin and Evolution of the Cretaceous Benue Trough. 28 Journal of African Earth Sciences, 8(2), 251-282.

Bertin J. (1976). Experimental and Theoretical Aspects of IP. Presentation and Application of the IP MethodCase Histories. Gebruder Borntraeger, Berlin, (1) 250. 
Braga A.C. (1999). Developments in geomechanical research for infrastructural projects, in 12th European Conference on Soil Mechanic and Geotechnical Engineering: Geotechnics, Special Issue, 52-55.

British Standards Institution BS 1377 (1990). - Methods of Test for soil for Civil Engineering Purposes, HMSO, London, p. 142.

Campanella R.G. and Weemees I, (1990). Development and Use of an Electrical Resistivity Cone for Groundwater Contamination Studies. Canadian Geotechnical Journal, 27, 557-590.

Cater, J.D. Barber W.D. (1963).The Geology of Parts of Adamawa, Bauchi and Borno provinces in Northeastern Nigeria - Bull geol. Surv. Nigeria, 30, 1 - 99.

Chang H.K. (1999).Correlation of Electrical Resistivity and Induced Polarization Data with Geotechnical Survey Standard Penetration Test Measurements. Journal of Environmental and Engineering Geophysics, 4, 123-130.

Collapse of Engineering Structures in (130). Conference on Soil Mechanics and Foundation Engineering pp.165-170.

Dike, E.F.C. (1995). Stratigraphy and structure of the Kerri - Kerri Basin, North eastern Nigeria. Journal of minerals Geology, 29 (1993), 77 - 93. 